\title{
Octavo Congreso de la Asociación de Estudios Bolivianos (AEB). Simposio «Objetos musicales. Patrimonio, conservación e investigación»
}

Sucre 20-24 de julio de 2015

\section{Gérard Borras}

\section{(2) OpenEdition}

12 Journals

\section{Edición electrónica}

URL: http://journals.openedition.org/bifea/7610

DOI: $10.4000 /$ bifea.7610

ISSN: 2076-5827

Editor

Institut Français d'Études Andines

\section{Edición impresa}

Fecha de publicación: 1 agosto 2015

Paginación: 300-302

ISSN: 0303-7495

\section{Referencia electrónica}

Gérard Borras, «Octavo Congreso de la Asociación de Estudios Bolivianos (AEB). Simposio «Objetos musicales. Patrimonio, conservación e investigación» », Bulletin de l'Institut français d'études andines [En línea], 44 (2) | 2015, Publicado el 08 agosto 2015, consultado el 06 noviembre 2020. URL : http:// journals.openedition.org/bifea/7610; DOI : https://doi.org/10.4000/bifea.7610

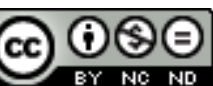

Les contenus du Bulletin de l'Institut français d'études andines sont mis à disposition selon les termes de la licence Creative Commons Attribution - Pas d'Utilisation Commerciale - Pas de Modification 4.0 International. 


\section{OCTAVO CONGRESO DE LA ASOCIACIÓN DE ESTUDIOS BOLIVIANOS (AEB). SIMPOSIO «OBJETOS MUSICALES. PATRIMONIO, CONSERVACIÓN E INVESTIGACIÓN»}

Sucre 20-24 de julio de 2015

Del 20 al 24 de julio de 2015 se realizó en la ciudad de Sucre el octavo congreso de la Asociación de Estudios Bolivianos (AEB). Treinta y tres simposios que congregaron a más de 300 investigadores que comunicaron y debatieron sobre temas de las ciencias sociales en las instalaciones del ABNB (Archivo Biblioteca Nacional de Bolivia), del Museo Nacional de Etnografía y Folklore (MUSEF-Sucre), de la Biblioteca Pública Gunnar Mendoza Loza y de la Casa de la Libertad. 
El IFEA apoyó cada una de las versiones del AEB y este año lo hizo también con la organización de un simposio dedicado a los objetos musicales en el marco del programa del IFEA dedicado a los temas de la música popular en el Perú y países andinos.

La propuesta partía de una constatación sencilla: la producción musical de tipo comercial conoció tempranamente una variedad significativa de soportes, de objetos sonoros: cajas musicales, cilindros de cera, rollos de pianola, discos de 78 rpm, etc. Sin embargo, otros objetos similares tienen mucha importancia y deben ser trabajados conjuntamente: partituras, cancioneros,

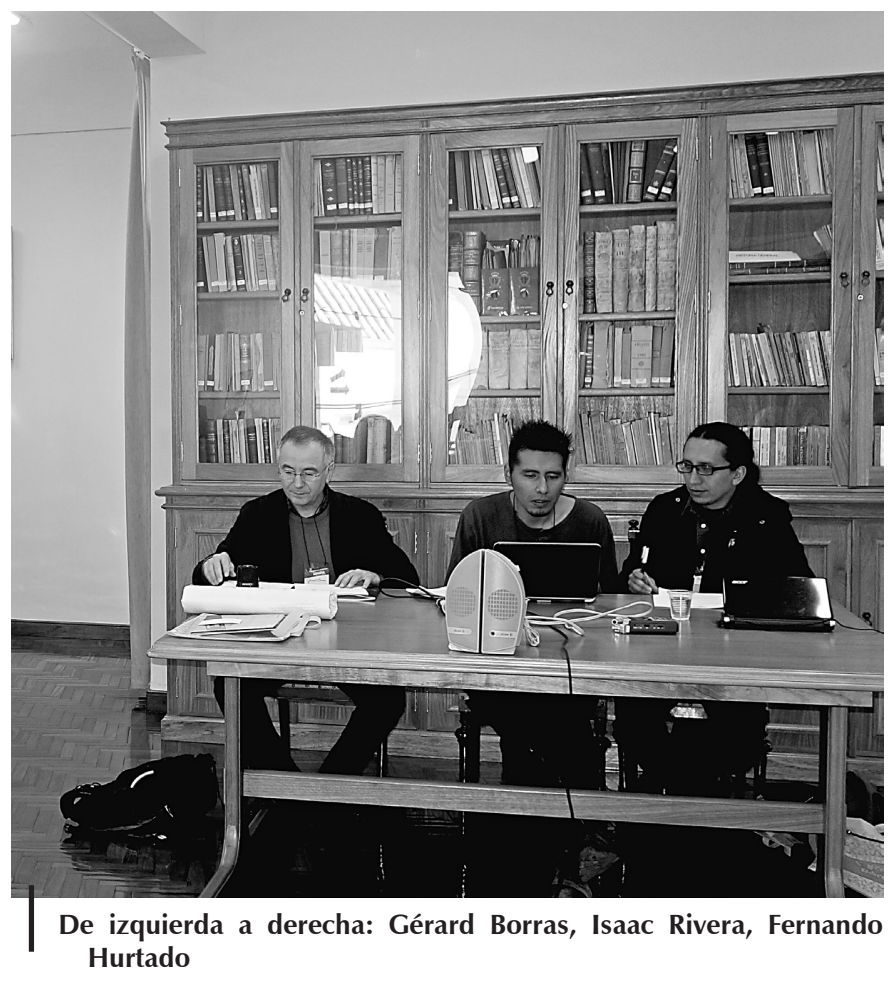
folletería, etc. La conservación, la recuperación de estos soportes es un verdadero reto y a la vez la promesa de avances significativos en el conocimiento y la comprensión de la historia de la música, en particular de la música popular. La propuesta articulaba entonces claramente dos aspectos: en primer lugar, la necesidad de reflexionar sobre las cuestiones archivísticas, que implican pensar el tema de la recuperación, catalogación, conservación de los materiales. En segundo lugar, la necesidad de revisar la aproximación a este tipo de investigación: ¿cómo trabajar estos objetos, en qué perspectiva, con qué herramientas y qué metodologías?

Para trabajar y dialogar sobre estos temas se habían reunidos a varios investigadores que tenían una experiencia en diferentes campos relacionados con la temática central. La idea era pensar el tema de los objetos musicales (sonoros y no sonoros) desde diferentes perspectivas: la de los historiadores, de los técnicos en acústica, de los sociólogos.

En la presentación del simposio, el coordinador Gérard Borras trazó un panorama de los desafíos desde la perspectiva de la historia cultural. Los objetos musicales no han sido necesariamente apreciados como lo merecían a la hora de pensar las representaciones sociales de las sociedades del siglo XX. Estas han producido cantidades de soportes e informaciones que nos permiten entender, desde diferentes puntos de vistas, lo que ha sido la producción musical en el contexto social del 
momento. Pero esto plantea numerosos problemas no resueltos: la situación parece idéntica en Perú y Bolivia, no existe una verdadera política de patrimonio que permitiera rescatar, conservar y valorar estos objetos. La otra parte de la intervención fue orientada hacia la parte metodológica del uso de estos materiales.

En su conferencia, Fred Rohner (Pontificia Universidad Católica del Perú) mostró cómo los objetos discos podían ser herramientas muy valiosas a la hora de entender las producciones, las circulaciones entre el sur peruano y la actual Bolivia. El disco y toda la información que lo rodea, permiten entender procesos, préstamos, influencias que hasta la fecha no habían sido identificados en esta zona.

Isaac Rivera y Fernando Hurtado que animan una página internet muy concurrida en la que difunden informaciones sobre música popular (los Ajayus de antaño), presentaron un panorama de la producción discográfica de principios de siglo XX en Bolivia, insistiendo en las dificultades que representa la colecta de los objetos discos ya que los repositorios oficiales no se encargan de estos soportes. La lectura de las revistas ilustradas, de los periódicos, de los anuncios publicitarios aparecen como contraparte esencial para mejor medir las recepciones de estas producciones.

Mauricio Sánchez (Universidad San Simón de Cochabamba) desde una perspectiva sociológica dibujó un panorama de los diferentes soportes audio que se habían producido en la segunda mitad del siglo XX y cómo estos objetos (discos, cassette, CD, minidisc) habían definido a la vez una cultura común y determinada sociabilidad en determinados grupos. La llegada de un disco nuevo, los préstamos de objetos sonoros, las escuchas individuales o colectivas giraban en torno al objeto cuyo impacto superaba lo estrictamente sonoro con sus códigos textuales y visuales.

El simposio contaba también con la participación de Arnaud Gérard (Acústica StudioLab, Potosí, Bolivia. Investigador asociado IIF/UMSA, La Paz, Bolivia.) que no pudo llegar por causa de los bloqueos que sitiaron la Villa Imperial durante varias semanas. El envío por correo eléctrónico de su ponencia fue un aporte a la reflexión global sobre la conservación de los objetos sonoros y la pérdida de información que estos sufren por el uso y el paso del tiempo en particular. Los debates en torno a la salvaguarda del patrimonio sonoro audiovisual pudieron ser enriquecidos por los aportes del cuarto seminario Internacional de archivos sonoros y audiovisuales. 